\title{
A Conceptual Model of Angelman Syndrome and Review of Relevant Clinical Outcomes Assessments (COAs)
}

\author{
Joseph C. Grieco ${ }^{1} \cdot$ Beverly Romero $^{2} \cdot$ Emuella Flood $^{2} \cdot$ Raquel Cabo $^{1} \cdot$ Jeannie Visootsak $^{1}$
}

Published online: 10 July 2018

(c) The Author(s) 2018

\begin{abstract}
Background Angelman syndrome (AS) is a rare, neurological genetic disorder for which no clinical outcomes assessments (COAs) or conceptual models (CM) have been developed.

Objective This study aimed to identify symptoms and impacts relevant and important in this patient population and develop a conceptual model of AS, and to evaluate the content validity of selected COA instruments with potential for inclusion in clinical studies of AS to capture treatment benefit.

Methods For both concept elicitation (CE) and cognitive interviews (CI), caregivers of children, adolescents, and adults with AS and clinicians with AS experience were targeted. For CI, clinicians discussed the Modified Performance-Oriented Mobility Assessment (MPOMA-G) and ProtoKinetics Zeno Walkway ${ }^{\mathrm{TM}}$ and caregivers reviewed the Pediatric Evaluation of Disability Inventory Computer Adaptive Test (PEDI-CAT), the Anxiety, Depression and Mood Scale (ADAMS), the Aberrant Behavior Checklist-Community (ABC-C), and the Morning Diary.

Results Four clinicians and 34 caregivers participated in CE interviews; three clinicians and 36 caregivers participated in CI. A conceptual model, initially informed by literature, was refined based on interview data. Five domains of symptoms, signs, and characteristics of AS were identified: cognitive and executive functioning, social-emotional, emotional-expressive behavior, sensory-compulsive behavior, and physical. Patient impacts were identified in three domains: activities of daily living, school, and social/community. Caregiver impacts were identified in five domains: mental health, physical health, work, home, and social. While all instruments demonstrated the ability to provide relevant data for the AS population, each instrument either contained some items irrelevant to individuals with AS or was missing important concepts based on the interviews. No single instrument covered all relevant domains specific to AS.
\end{abstract}

Conclusion Future work should consider the adaptation of existing COAs and the development of a novel AS-specific instrument for use in clinical research to ensure outcomes important to this patient population are captured.

Electronic supplementary material The online version of this article (https://doi.org/10.1007/s40271-018-0323-7) contains supplementary material, which is available to authorized users.

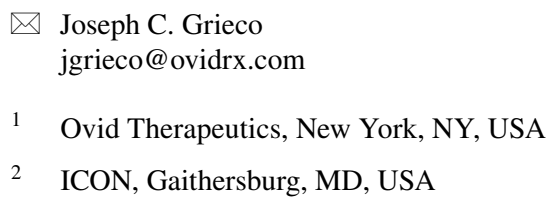




\section{Key Points for Decision Makers}

A conceptual model depicting the signs, symptoms, and impacts of Angelman syndrome (AS) based on existing literature and interviews with clinicians and caregivers provides a framework from which to select, adapt, or develop an appropriate clinical outcomes assessment (COA) tool for AS.

While, no single existing COA addresses all symptoms and experiences of individuals with AS, there are some outcomes assessments that include items relevant to elicited concepts in AS; adaptation of these instruments for use in the AS population should be explored.

The development of a COA that is fit-for-purpose for individuals with AS is important in being able to appropriately assess symptoms and experiences of such individuals in order to capture treatment benefit in drug development programs.

\section{Introduction}

Angelman syndrome (AS) is a rare, neurological genetic disorder characterized by developmental delays, learning disabilities, severe speech impairment, and ataxia [1-3]. The prevalence of AS, which affects all racial/ethnic groups and both males and females equally, has been estimated to be approximately one in 10,000 to 40,000 people in the general population. However, this figure may be underestimated, as many cases go undiagnosed [3].

As research in AS progresses, it is important to understand the patient experience and the outcomes of greatest relevance and importance to patients and/or their caregivers in the evaluation of new treatments. This patient-centered approach is underscored by the US Food and Drug Administration's (FDA) Patient-Focused Drug Development (PFDD) initiative, which is designed to ensure that the patient perspective is considered in drug development and evaluation, including the identification of relevant endpoints and the collection of patient-reported or observer-reported information from well defined and reliable clinical outcomes assessments (COAs) to inform decision making [4-6]. Clinical study results measured by a well defined and reliable COA in appropriately designed investigations can be used to support a claim in medical product labeling [4].

To date, no AS-specific COA instruments have been developed. Instead, a number of existing COAs developed for pediatric populations or other conditions similar to AS have been used to capture treatment benefit in clinical trials [7-14]. However, these instruments have not been fully evaluated to determine whether they are content valid or fitfor-purpose in AS clinical trials. The lack of disease-specific COAs developed for the AS population can lead to unreliable results in controlled clinical trials that assess treatment effect [15].

There is no prior research that has systematically explored the patient and/or caregiver perspectives of the symptoms and impacts associated with AS, nor has a conceptual model of AS been previously published. A conceptual model of a disease or condition is a useful tool for informing a COA measurement strategy, as it depicts the signs, symptoms, and impacts of the condition and can help identify relevant concepts that could be impacted by treatment and should be measured to capture treatment benefit [16]. The objectives of this study were to identify symptoms and impacts relevant and important in this patient population, develop a conceptual model of AS, and to evaluate the content validity of selected COA instruments that have the potential for inclusion in clinical studies of AS to capture treatment benefit.

\section{Methods}

\subsection{Overview of Methods}

Concept elicitation (CE) interviews with clinicians and caregivers of children, adolescents, and adults with AS were conducted, followed by cognitive interviews (CI) to assess a set of five COA instruments. The following COAs were selected based on a previously conducted literature review $[17,18]$ for potential use with children and adults with AS: the Modified Performance-Oriented Mobility Assessment (MPOMA-G), ProtoKinetics Zeno Walkway ${ }^{\mathrm{TM}}$ (Protokinetics, Havertown, PA, USA), the Pediatric Evaluation of Disability Inventory Computer Adaptive Test (PEDI-CAT), the Anxiety, Depression and Mood Scale (ADAMS), and the Aberrant Behavior Checklist-Community (ABC-C). The criteria for instrument selection included frequent use in AS or other mimicking disorders, prior use in a clinical trial, and a high likelihood of mapping to relevant concepts in AS. In addition, a previously unvalidated sleep diary (the Morning Diary) that was developed for a specific trial in AS to capture key concepts on sleep was included in the evaluation [19]. 


\subsection{Eligibility Criteria and Recruitment}

With a target sample of 36 caregivers for CE and CI, participants were required to be the primary caregiver ${ }^{1}$ of a child/ adolescent with AS aged 5-17 years, inclusive, or an adult with AS aged 18 years or over, with a molecular confirmation of diagnosis. Caregivers were excluded if the patient was non-ambulatory. Caregivers were recruited through patient advocacy groups (PAGs), utilizing online postings, emails, and social media. Study staff screened all participants via telephone.

Five clinicians were targeted for both $\mathrm{CI}$ and $\mathrm{CE}$ interviews. Clinicians had to have a doctoral degree with 2 years of clinical experience with AS, or be a physiotherapist, occupational therapist, or physical therapist, or have a Master's degree in a medical, educational, or psychology-related field with 2 years of experience with AS patients. They also had to consult or treat at least two AS patients in the past 12 months. For CI, preference was given to physicians who were both currently treating patients with AS and had prior experience with the instruments under review.

\subsection{Study Procedures}

Both clinician and caregiver CE interviews were conducted by experienced interviewers via telephone, although caregivers were given the option of a face-to-face interview. Interviews followed a semi-structured interview guide (see Supplemental Appendix in electronic supplementary material [ESM]) and were audio recorded with the participant's permission. Caregivers also completed a socio-demographic questionnaire. Clinician interviews lasted approximately $60 \mathrm{~min}$, and caregiver interviews lasted approximately 120 min. Clinician participants received \$350 USD and caregiver participants were remunerated $\$ 150$ USD for their time.

For CI, clinicians reviewed the MPOMA-G and the Zeno Walkway ${ }^{\mathrm{TM}}$. The MPOMA-G is a clinician-completed measure that provides an overall score on gait based on the clinician's observation of step length and height, step symmetry, step continuity, trunk sway, and walk stance [20]. The Zeno Walkway ${ }^{\mathrm{TM}}$ is an electronic floor mat that captures and analyzes multiple parameters of an individual's gait [21]. Clinicians received a copy of the MPOMA-G and related training materials prior to the interview. Interviews were conducted via telephone, lasted approximately $90 \mathrm{~min}$, were audio recorded with permission, and followed a semi-structured guide (Supplemental Appendix, see ESM).

\footnotetext{
1 'Primary' caregiver is defined as having contact with the patient on most days for most of the time that the patient was at home over the past year.
}

Caregivers reviewed four observer-reported outcomes measures (ObsROs): the PEDI-CAT, the ABC-C, the ADAMS, and the Morning Diary. The PEDI-CAT is a computer adaptive test designed for observation of children and young adults through age 21 years [22]. The full PEDI-CAT covers four domains: mobility, daily activities, social cognitive, and responsibility; however, only the mobility and daily activities modules were evaluated in this study, as these domains were more relevant to the cognitive skills of those with AS and most likely to demonstrate treatment benefit among those with AS. The mobility module item bank has 75 items, and the daily activities module item bank has 68 items. Since this is a computer adaptive test, caregivers did not see all items while taking the PEDI-CAT, but they were asked about each item in these two domains during the interview.

The ADAMS is a 28 -item questionnaire measuring moodrelated behaviors in those with an intellectual disability [23], and the ABC-C consists of 58 items focusing on aberrant behaviors, such as hyperactivity, irritability, lethargy/social withdrawal, stereotypic behavior, and inappropriate speech [24].

The Morning Diary [19] is an electronic sleep diary developed specifically for use with individuals with AS. It has two modules, one for caregivers to complete about the patient and one for caregivers to complete about themselves. Caregivers reviewed screenshots of the electronic diary.

Due to the length of the instruments, caregivers participated in three in-person cognitive interviews, each lasting approximately $90 \mathrm{~min}$. The ABC-C and PEDI-CAT were discussed in separate interviews, and the ADAMS and Morning Diary were discussed in the same interview. The order of administration was altered with each interview. After completing the instrument, the caregiver responded to questions about each item's ease of completion, meaning, and relevancy. Interviews were audio recorded with permission. Caregivers were remunerated \$150 USD for each of the three cognitive interviews. Interviews took place across the United States, with participants having the option to either hold the interviews at home or at a neutral location nearby.

\subsubsection{Analysis}

Verbatim transcripts were developed from the audio recordings and reviewed by members of the study team to remove any identifying data and correct any transcription errors. For CE, a content and thematic analytic approach was used [25]. MaxQDA, a qualitative analysis software program, was used to help organize the data and code the transcripts [26]. For CE, initial transcripts were coded by each of the participating coders ( 7 in total) to ensure consistency in the application of codes. Data saturation, the point at which no new concepts emerged from analyzed interview data, was 
evaluated using a data saturation matrix [27]. For CI, interviews were coded using MaxQDA, with a specific focus on identifying any issues related to clarity, comprehensiveness, or relevance. Demographic information for both phases was summarized using descriptive statistics.

\subsubsection{Ethics}

The study received approval from a central institutional review board (IRB), Salus IRB (Austin, TX, USA). All participants provided written informed consent prior to being interviewed.

\section{Results}

\subsection{Sample Characteristics}

Four clinicians were successfully recruited to participate in CE. Of these four, two also participated in CI. One new clinician was recruited to participate in CI, for a total of three clinicians.

Of the four clinicians completing CE interviews, two specialized in genetics, one was a behavioral psychologist, and one was a psychiatrist who works with both adults and children. The clinicians currently treated an average of 14 patients (range 2-30) with AS, and had treated an average of 65 patients (range 40-100) with AS over the course of their careers. Three clinicians practiced primarily in an academic setting affiliated with a children's hospital, while one practiced privately and at a children's hospital.

For CI, two of the clinicians from CE completed interviews. While an expert on AS, one of these clinicians was not an expert on gait, the focus of the instruments under evaluation. One new clinician participated in this phase, a physical therapist (PT) who had no current patients with AS, but had treated 10 over the course of his career. This PT practiced in an academic setting affiliated with a children's hospital.

A total of 36 caregivers were interviewed for CE; however, two participants were found to lack molecular confirmation based on questionnaire responses (1 child and 1 adolescent) and were removed from the dataset, resulting in a total of 34 caregiver interviews representing three patient age groups (11 children, 11 adolescents, and 12 adults). Patients had a mean (SD) age of 15.7 (7.43) years (range 5-35 years), and the racial/ethnic breakdown was 88.2\% White/Caucasian, 2.9\% Asian, and 8.8\% Hispanic. Patients had a mean (SD) of 12.8 (6.6) years since diagnosis (Table 1). All caregiver participants were female, and the mean (SD) age was $45.8(10.2)$ years. More than half the sample (58.9\%) had a college degree or higher, and $76.5 \%$ were employed full- or part-time (Table 2). Saturation was attained by the 26th interview, supporting the adequacy of the sample.

Thirty-three of the original 34 caregivers also participated in CI. One caregiver did not participate in CI, as the participant's child was determined to be non-ambulatory during the course of the interview. While technically ineligible, the participant was still able to provide valuable insight on the impacts of AS. As such, it was decided to include this participant's data in the CE analysis but to replace them for Phase 2 (CI). Three new caregivers, who had previously shown interest in the study, were screened and enrolled in the study for CI only for a total sample of 36 caregivers completing CI (See Table 3 for caregiver characteristics and Table 4 for patient characteristics).

\subsection{Conceptual Model Development}

A preliminary conceptual model was drafted based on the results of a previously conducted literature review $[17,18]$. The conceptual model was refined upon completion of the concept elicitation interviews. The final model (Figs. 1, 2, and 3) demonstrates the signs, symptoms and characteristics of AS, as well as impacts on both the patients and the caregivers. Sample quotes illustrating selected concepts from each domain represented in the model are provided in Tables 5 and 6.

\subsubsection{Cognitive and Executive Function}

Difficulties and/or disorders related to cognitive and executive functioning are key defining characteristics of AS. These include deficits in intellectual functioning, seizures, short attention span, hyperactivity/restlessness, impulsivity, an impaired recognition of danger, and memory issues. All were discussed in the interviews. Memory issues were included in the preliminary model based on the literature but were not mentioned during the interviews.

Of particular note, seizures $(34,100 \%)$, difficulty paying attention $(34,100 \%)$, and hyperactivity/restlessness $(30,88 \%)$ were reported by the majority of caregivers and clinicians. A number of caregivers $(13,38 \%)$ described an improvement in their child's seizures with increasing age, with none reporting that seizures had worsened. However, a few noted that the seizures changed in other ways, such as seizure type or trigger(s). The improvement of seizures over the lifespan was corroborated by the clinicians, who all reported that seizures tended to be more severe in childhood and improved in adolescence or adulthood. Caregivers, as well as one of the clinicians, also noted improvement in attention and hyperactivity/restlessness with age. 
Table 1 Patient characteristics-concept elicitation

\begin{tabular}{|c|c|c|c|c|}
\hline Patient socio-demographic characteristics & $\begin{array}{l}\text { Children } \\
n=11\end{array}$ & $\begin{array}{l}\text { Adolescents } \\
n=11\end{array}$ & $\begin{array}{l}\text { Adults } \\
n=12\end{array}$ & $\begin{array}{l}\text { Total } \\
n=34\end{array}$ \\
\hline \multicolumn{5}{|l|}{ Gender } \\
\hline Male & $6(54.5 \%)$ & $6(54.5 \%)$ & $6(50.0 \%)$ & $17(50.0 \%)$ \\
\hline Female & $5(45.5 \%)$ & $5(45.5 \%)$ & $6(50.0 \%)$ & $17(50.0 \%)$ \\
\hline \multicolumn{5}{|l|}{ Age (years) } \\
\hline Mean (SD) & $7.9(2.26)$ & $15.0(1.00)$ & $23.6(5.35)$ & $15.7(7.43)$ \\
\hline Median & 8 & 15 & 21.5 & 15 \\
\hline Min, $\max$ & 5,12 & 14,17 & 18,35 & 5,35 \\
\hline \multicolumn{5}{|l|}{ Race/ethnicity } \\
\hline Caucasian & $9(81.8 \%)$ & $10(90.9 \%)$ & $11(91.7 \%)$ & $30(88.2 \%)$ \\
\hline Asian & $1(9.1 \%)$ & & & $1(2.9 \%)$ \\
\hline \multicolumn{5}{|l|}{ Black } \\
\hline Hispanic & $1(9.1 \%)$ & $1(9.1 \%)$ & $1(8.3 \%)$ & $3(8.8 \%)$ \\
\hline \multicolumn{5}{|l|}{ Time since diagnosis (years) } \\
\hline Mean (SD) & $6.4(2.6)$ & $11.6(3.8)$ & $19.8(4.0)$ & $12.8(6.6)$ \\
\hline Median & 6.8 & 13.0 & 17.7 & 13.3 \\
\hline Min, $\max$ & $2.3,11.9$ & $4.9,16.1$ & $14.2,26.8$ & $2.3,26.8$ \\
\hline \multicolumn{5}{|l|}{ Type of Angelman syndrome } \\
\hline Small deletion & $2(18.2 \%)$ & $1(9.1 \%)$ & $3(25 \%)$ & $6(17.6 \%)$ \\
\hline Large deletion & $3(27.3 \%)$ & $2(18.2 \%)$ & $2(16.7 \%)$ & $7(20.6 \%)$ \\
\hline Deletion $+($ size unknown $)$ & & $1(9.1 \%)$ & $4(41.7 \%)$ & $5(14.7 \%)$ \\
\hline Mutation & $2(18.2 \%)$ & $2(18.2 \%)^{\mathrm{a}}$ & $2(16.7 \%)$ & $6(17.6 \%)$ \\
\hline Imprinting center defect & $2(18.2 \%)$ & $1(9.1 \%)$ & & $3(8.8 \%)$ \\
\hline Uniparental disomy & $1(9.1 \%)$ & $1(9.1 \%)$ & & $2(5.9 \%)$ \\
\hline Mosaic & & $1(9.1 \%)^{\mathrm{a}}$ & & $1(2.9 \%)$ \\
\hline Unknown & & $1(9.1 \%)$ & $1(8.3 \%)$ & $2(5.9 \%)$ \\
\hline Abnormal methylation pattern & & $1(9.1 \%)$ & & $1(2.9 \%)$ \\
\hline Not reported & $1(9.1 \%)$ & $1(9.1 \%)$ & & $2(5.9 \%)$ \\
\hline
\end{tabular}

${ }^{\mathrm{a}}$ One participant indicated they were both mosaic and mutation

\subsubsection{Social-Emotional}

The social-emotional domain describes the patient in relation to his/her interactions with others and related emotions. These include communication difficulties, anxiety, being overly friendly with strangers, gregariousness and a happy demeanor, as well as lacking social inhibitions/ being socially inappropriate, being easily excitable, resistance to/difficulty with change, and frustration.

Communication difficulties were especially important and were discussed by all caregivers and clinicians during CE. Most caregivers described their child as 'non-verbal,' though some reported use of limited verbal language. Communication might improve over time in the form of increased number of signs, gestures or word approximations, but patients, in general, remained non-verbal across the lifespan. Communication difficulties could lead to frustration for both patient and caregiver, as well as behavioral problems due to the patient's inability to express wants or needs.
Patients with AS were noted to be happy and social, with a tendency towards over-friendly behavior with strangers. Most caregivers $(32,94 \%)$ also reported that their child was easily excitable. There was variability in whether or not excitability changed over the lifespan, and some noted a close relationship to anxiety.

Anxiety was reported by most caregivers $(27,79 \%)$ and all of the clinicians. Of the 27 patients with anxiety, nine were adults, eight were children, and ten were adolescents. Caregivers perceived anxiety in their child through his/her actions, body language, and vocalizations. Anxiety could be triggered by crowds, new environments, poor sleep, and/or meeting new people.

\subsubsection{Emotional-Expressive Behavior}

Emotional-expressive behaviors were noted in the qualitative interviews and include behaviors that individuals with AS might use as a means to communicate or express themselves. All caregivers reported that their child, either previously or 
Table 2 Caregiver characteristics-concept elicitation

\begin{tabular}{|c|c|c|c|c|}
\hline $\begin{array}{l}\text { Caregiver socio-demographic } \\
\text { characteristics }\end{array}$ & $\begin{array}{l}\text { Children } \\
n=11\end{array}$ & $\begin{array}{l}\text { Adolescents } \\
n=11\end{array}$ & $\begin{array}{l}\text { Adults } \\
n=12\end{array}$ & $\begin{array}{l}\text { Total } \\
n=34\end{array}$ \\
\hline \multicolumn{5}{|l|}{ Gender } \\
\hline Female & $12(100.0 \%)$ & $11(100.0 \%)$ & $12(100.0 \%)$ & $34(100.0 \%)$ \\
\hline \multicolumn{5}{|l|}{ Age (years) } \\
\hline Mean (SD) & $38.7(9.98)$ & $44(5.50)$ & $54(7.76)$ & $45.8(10.2)$ \\
\hline Median & 35.0 & 44 & 55.5 & 45 \\
\hline Min, $\max$ & 29,63 & 36,54 & 36,70 & 29,70 \\
\hline \multicolumn{5}{|l|}{ Race/ethnicity } \\
\hline Caucasian & $9(81.8 \%)$ & $10(90.9 \%)$ & $11(91.7 \%)$ & $30(88.2 \%)$ \\
\hline Asian & $1(9.1 \%)$ & & & $1(2.9 \%)$ \\
\hline \multicolumn{5}{|l|}{ Black } \\
\hline Hispanic & $1(9.1 \%)$ & $1(9.1 \%)$ & $1(8.3 \%)$ & $3(8.8 \%)$ \\
\hline \multicolumn{5}{|l|}{ Education } \\
\hline High school & - & $1(9.1 \%)$ & & $1(2.9 \%)$ \\
\hline Trade school & $1(9.1 \%)$ & & & \\
\hline Associates degree & $4(36.4 \%)$ & $1(9.1 \%)$ & $2(16.7 \%)$ & $4(11.8 \%)$ \\
\hline Some college & $4(36.4 \%)$ & $4(36.4 \%)$ & $1(8.3 \%)$ & $9(26.5 \%)$ \\
\hline College graduate & $2(18.2 \%)$ & $1(9.1 \%)$ & $6(50.0 \%)$ & $11(32.4 \%)$ \\
\hline Graduate degree & & $4(36.4 \%)$ & $3(25.0 \%)$ & $9(26.5 \%)$ \\
\hline \multicolumn{5}{|l|}{ Employment } \\
\hline Full-time & $4(36.4 \%)$ & $9(81.8 \%)$ & $6(50.0 \%)$ & $19(55.9 \%)$ \\
\hline Part-time & $3(27.3 \%)$ & $1(9.1 \%)$ & $3(25.0 \%)$ & $7(20.6 \%)$ \\
\hline Retired & & & $2(16.7 \%)$ & $2(5.9 \%)$ \\
\hline \multicolumn{5}{|l|}{ Student } \\
\hline Homemaker & $4(36.4 \%)$ & $1(9.1 \%)$ & & $5(14.7 \%)$ \\
\hline Unemployed/disabled & & & $1(8.3 \%)$ & $1(2.9 \%)$ \\
\hline \multicolumn{5}{|l|}{ Relationship to patient } \\
\hline Parent & $10(90.9 \%)$ & $11(100.0 \%)$ & $12(100.0 \%)$ & $33(97.1 \%)$ \\
\hline Grandparent & $1(9.1 \%)$ & & & $1(2.9 \%)$ \\
\hline \multicolumn{5}{|l|}{ Marital status } \\
\hline Single & $4(36.4 \%)$ & $2(18.2 \%)$ & $1(8.3 \%)$ & $7(20.6 \%)$ \\
\hline Married & $7(63.6 \%)$ & $9(81.8 \%)$ & $11(91.7 \%)$ & $27(79.4 \%)$ \\
\hline
\end{tabular}

currently, exhibits some form of the following behaviors: aggressive behavior (26, 76\%), inappropriate laughing (26, $76 \%$ ), acting in an uncooperative/stubborn/demanding way $(14,41 \%)$, destructive behavior $(11,32 \%)$, and yelling $(10$, $29 \%)$. Included in the definition of aggressive behaviors were hitting $(15,44 \%)$, hair pulling $(14,41 \%)$, pinching $(10$, $29 \%$ ) and general aggressiveness $(9,26 \%)$. Caregivers commonly reported that these behaviors were instrumental and goal-driven. All four clinicians also discussed behavioral issues as a characteristic of AS, with two clinicians particularly noting the resulting family impact.

Caregivers offered a variety of tactics for managing emotional-expressive behaviors, including going outside, separating from the situation, giving the individual a break, and taking the patient to a quiet place. Only one caregiver described the behaviors as only a concern of the past. Changes in behaviors over time were highly variable. Six caregivers reported neither a positive nor negative change, eight reported improvement with increasing age, and ten reported worsening over time. Eight of the ten caregivers reporting worsening behavior over time are caregivers of children or teens rather than adults.

\subsubsection{Sensory-Compulsive Behavior}

Sensory-compulsive behaviors include water fascination, fascination with paper or other crinkly objects, stereotyped behavior, compulsions, abnormal food behaviors, and mouthing/chewing inedible objects. Rituals was included in the preliminary model but not reported during $\mathrm{CE}$. Of all of the reported sensory-compulsive behaviors, the most frequently reported were water fascination $(29,85 \%)$ and obsession with food $(14,41 \%)$. Water fascination was described as loving to swim and take baths, enjoying moving water, and/ 
Table 3 Caregiver sample characteristics-cognitive interviews

\begin{tabular}{|c|c|c|c|c|}
\hline Socio-demographic characteristics & $\begin{array}{l}\text { Children } \\
n=12\end{array}$ & $\begin{array}{l}\text { Adolescents } \\
n=12\end{array}$ & $\begin{array}{l}\text { Adults } \\
n=12\end{array}$ & $\begin{array}{l}\text { Total } \\
n=36\end{array}$ \\
\hline \multicolumn{5}{|l|}{ Gender } \\
\hline Male & $0(0.0 \%)$ & $0(0 \%)$ & $0(0.0 \%)$ & $0(0 \%)$ \\
\hline Female & $12(100.0 \%)$ & $12(100 \%)$ & $12(100.0 \%)$ & $36(100 \%)$ \\
\hline \multicolumn{5}{|l|}{ Age (years) } \\
\hline Mean (SD) & $39(8.72)$ & $44(5.14)$ & $54(7.76)$ & $45.7(9.59)$ \\
\hline Median & 36.5 & 43.5 & 55.5 & 45 \\
\hline Min, max & 29,63 & 36,54 & 36,70 & 29,70 \\
\hline \multicolumn{5}{|l|}{ Race/ethnicity } \\
\hline Caucasian & $10(83.3 \%)$ & $11(91.7 \%)$ & $11(91.7 \%)$ & $32(88.9 \%)$ \\
\hline Asian & $1(8.3 \%)$ & & & $1(2.8 \%)$ \\
\hline \multicolumn{5}{|l|}{ Black } \\
\hline Hispanic & $1(8.3 \%)$ & $1(8.3 \%)$ & $1(8.3 \%)$ & $3(8.3 \%)$ \\
\hline \multicolumn{5}{|l|}{ Education } \\
\hline High school & & $1(8.3 \%)$ & & $1(2.8 \%)$ \\
\hline \multicolumn{5}{|l|}{ Trade school } \\
\hline Associates degree & $1(8.3 \%)$ & $1(8.3 \%)$ & $2(16.7 \%)$ & $4(11.1 \%)$ \\
\hline Some college & $4(33.3 \%)$ & $5(41.7 \%)$ & $1(8.3 \%)$ & $10(27.8 \%)$ \\
\hline College graduate & $5(41.7 \%)$ & $1(8.3 \%)$ & $6(50.0 \%)$ & $12(33.3 \%)$ \\
\hline Graduate degree & $2(16.7 \%)$ & $4(33.3 \%)$ & $3(25.0 \%)$ & $9(25.0 \%)$ \\
\hline \multicolumn{5}{|l|}{ Employment } \\
\hline Full-time & $3(25.0 \%)$ & $10(83.3 \%)$ & $6(50.0 \%)$ & $19(52.8 \%)$ \\
\hline Part-time & $4(33.3 \%)$ & $1(8.3 \%)$ & $3(25.0 \%)$ & $8(22.2 \%)$ \\
\hline Retired & & & $2(16.7 \%)$ & $2(5.6 \%)$ \\
\hline \multicolumn{5}{|l|}{ Student } \\
\hline Homemaker & $5(41.7 \%)$ & $1(8.3 \%)$ & & $6(16.7 \%)$ \\
\hline Unemployed, disabled & & & $1(8.3 \%)$ & $1(2.8 \%)$ \\
\hline \multicolumn{5}{|l|}{ Relationship to patient } \\
\hline Parent & $11(91.7 \%)$ & $12(100.0 \%)$ & $12(100.0 \%)$ & $35(97.2 \%)$ \\
\hline Grandparent & $1(8.3 \%)$ & & & $1(2.8 \%)$ \\
\hline \multicolumn{5}{|l|}{ Marital status } \\
\hline Single & $3(25.0 \%)$ & $3(25.0 \%)$ & $1(8.3 \%)$ & $7(19.4 \%)$ \\
\hline Married & $9(75.0 \%)$ & $9(75.0 \%)$ & $11(91.7 \%)$ & $29(80.6 \%)$ \\
\hline
\end{tabular}

or bubbles. Among those who reported a change over time, caregivers of children and adults most commonly reported a decrease, whereas caregivers of teens reported no change.

None of the caregivers reporting on an obsession with food noted improvement over time. Three caregivers reported a worsening over time, and the others reported no change.

\subsubsection{Physical}

The physical domain includes problems with mobility, difficulty with fine and gross motor skills, eating problems, reflux, constipation, and sleep problems, among others. Ear infections, gagging (not related to eating), and reflux were not included in the preliminary model and were added based on clinician and/or caregiver interviews, while physical impacts of laughing were not noted during interviews but included in the preliminary model.

The majority of caregivers $(33,97 \%)$ and all clinicians reported problems with mobility. Common themes included balance-related problems, difficulty with gait, ataxia, the need for assistance or assistive devices, and problems with stairs. Muscular issues were noted to be age-specific, such as hypotonia in young children followed by hypertonia, spasticity and possibly contracture as they age.

The majority of caregivers $(27,79 \%)$ reported sleep problems, such as difficulty falling and staying asleep, need for less sleep, and not being able to sleep alone, among others. All clinicians also reported sleep problems as a common characteristic of AS. Many caregivers reported that the patient took and benefited from sleep aids, such as melatonin and trazodone. Fifteen caregivers, and three of the clinicians, 
Table 4 Patient sample characteristics-cognitive interviews

\begin{tabular}{|c|c|c|c|c|}
\hline Socio-demographic characteristics & $\begin{array}{l}\text { Children } \\
n=12\end{array}$ & $\begin{array}{l}\text { Adolescents } \\
n=12\end{array}$ & $\begin{array}{l}\text { Adults } \\
n=12\end{array}$ & $\begin{array}{l}\text { Total } \\
n=36\end{array}$ \\
\hline \multicolumn{5}{|l|}{ Gender } \\
\hline Male & $6(50.0 \%)$ & $7(58.3 \%)$ & $6(50.0 \%)$ & $19(52.8 \%)$ \\
\hline Female & $6(50.0 \%)$ & $5(41.7 \%)$ & $6(50.0 \%)$ & $17(47.2 \%)$ \\
\hline \multicolumn{5}{|l|}{ Age (years) } \\
\hline Mean (SD) & $7.7(2.21)$ & $15(0.91)$ & $23.6(5.35)$ & $15.4(7.33)$ \\
\hline Median & 7.5 & 15 & 21.5 & 15 \\
\hline Min, $\max$ & 5,12 & 14,17 & 18,35 & 5,35 \\
\hline \multicolumn{5}{|l|}{ Race/ethnicity } \\
\hline Caucasian & $10(83.3 \%)$ & $11(91.7 \%)$ & $11(91.7 \%)$ & $32(88.9 \%)$ \\
\hline Asian & $1(8.3 \%)$ & & & $1(2.8 \%)$ \\
\hline \multicolumn{5}{|l|}{ Black } \\
\hline Hispanic & $1(8.3 \%)$ & $1(8.3 \%)$ & $1(8.3 \%)$ & $3(8.3 \%)$ \\
\hline \multicolumn{5}{|l|}{ Type of Angelman syndrome } \\
\hline Small deletion & $2(16.7 \%)$ & $3(25 \%)$ & $2(16.7 \%)$ & $7(19.4 \%)$ \\
\hline Large deletion & $3(25 \%)$ & $2(16.7 \%)$ & $1(8.3 \%)$ & $6(16.7 \%)$ \\
\hline Deletion + (size unknown) & & $1(8.3 \%)$ & $6(50 \%)$ & $7(19.4 \%)$ \\
\hline Mutation & $2(16.7 \%)$ & $2(16.7 \%)^{\mathrm{a}}$ & $2(16.7 \%)$ & $6(16.7 \%)$ \\
\hline Imprinting center defect & $2(16.7 \%)$ & $1(8.3 \%)$ & & $3(8.3 \%)$ \\
\hline Uniparental disomy & $1(8.3 \%)$ & $1(8.3 \%)$ & & $2(5.6 \%)$ \\
\hline Mosaic & $1(8.3 \%)$ & $1(8.3 \%)^{\mathrm{a}}$ & & $2(5.6 \%)$ \\
\hline Abnormal methylation pattern & & $1(8.3 \%)$ & & $1(2.8 \%)$ \\
\hline Unknown & & $1(8.3 \%)$ & $1(8.3 \%)$ & $2(5.6 \%)$ \\
\hline Not reported & $1(8.3 \%)$ & & & $1(2.8 \%)$ \\
\hline
\end{tabular}

${ }^{\mathrm{a}}$ One participant indicated they were both mosaic and mutation

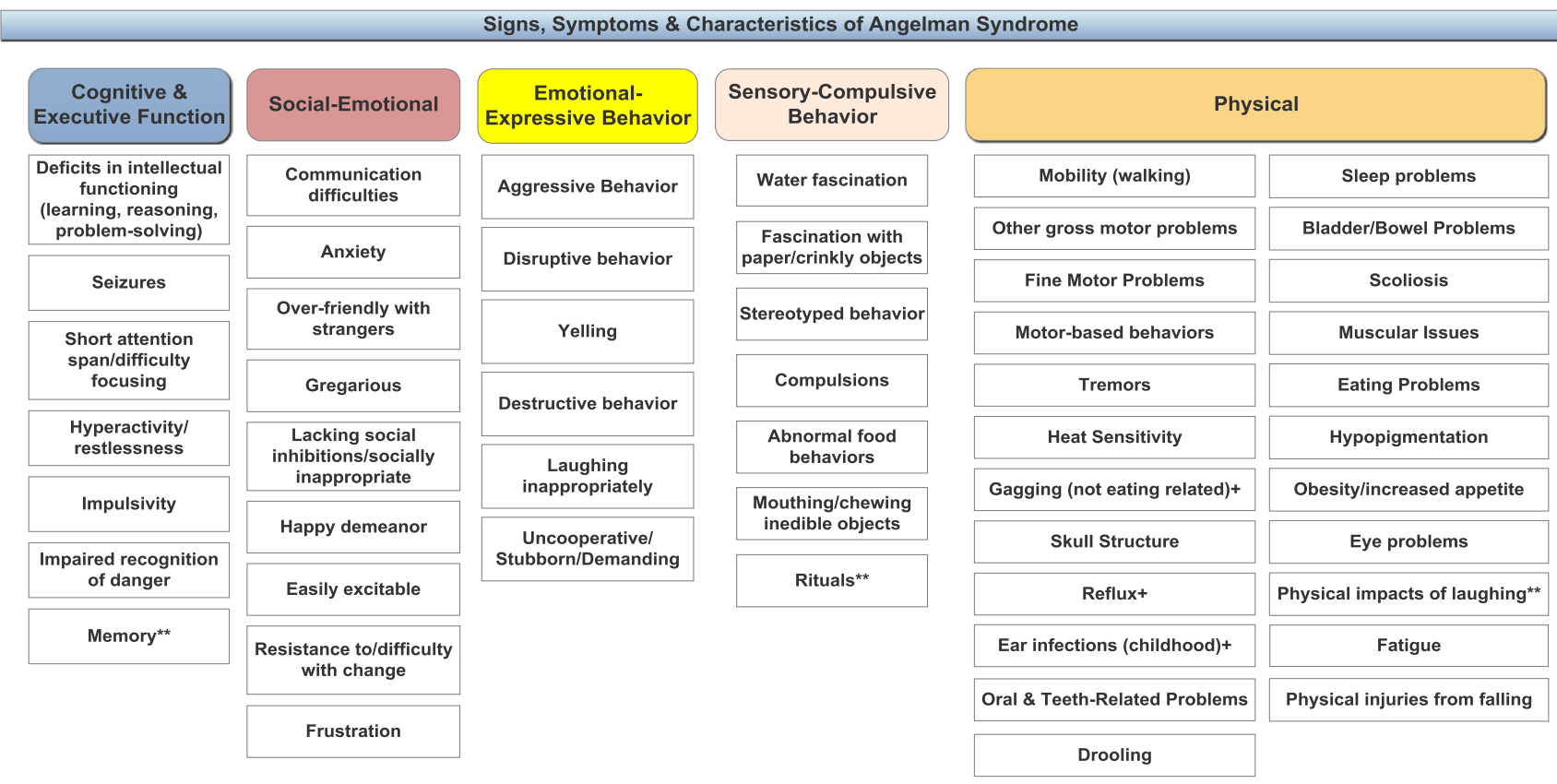

Key:

** Literature review only

+ Caregiver and/or clinician interviews only

Fig. 1 Signs, symptoms, and characteristics of Angelman syndrome 
Fig. 2 Patient impacts

\section{Patient Impacts}

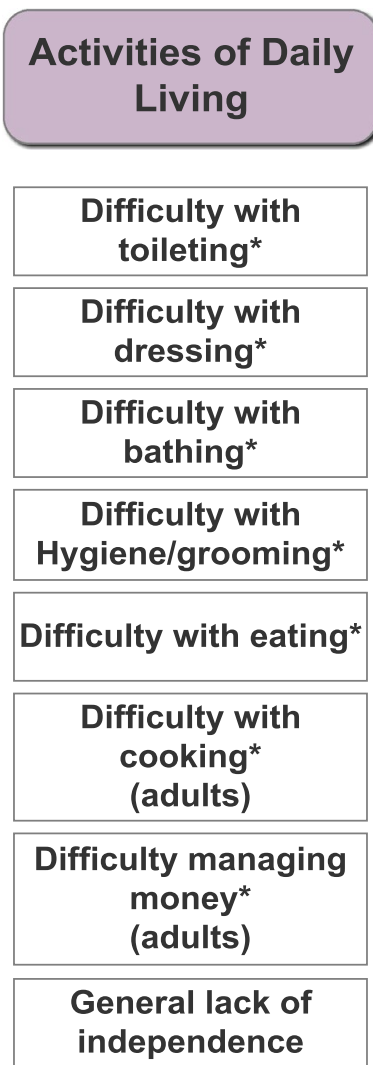

School

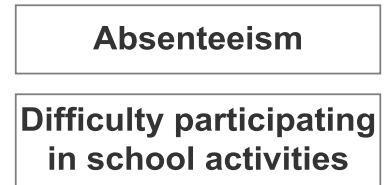

Difficulty learning and concentrating

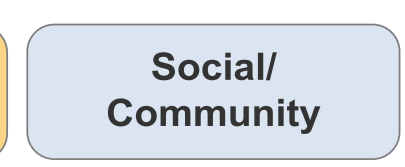

\begin{tabular}{|c|}
\hline $\begin{array}{c}\text { Difficulty making/ } \\
\text { keeping friends }\end{array}$ \\
\hline $\begin{array}{c}\text { Impacts sibling } \\
\text { relationships }\end{array}$ \\
\hline
\end{tabular}

Impacts other family relationships

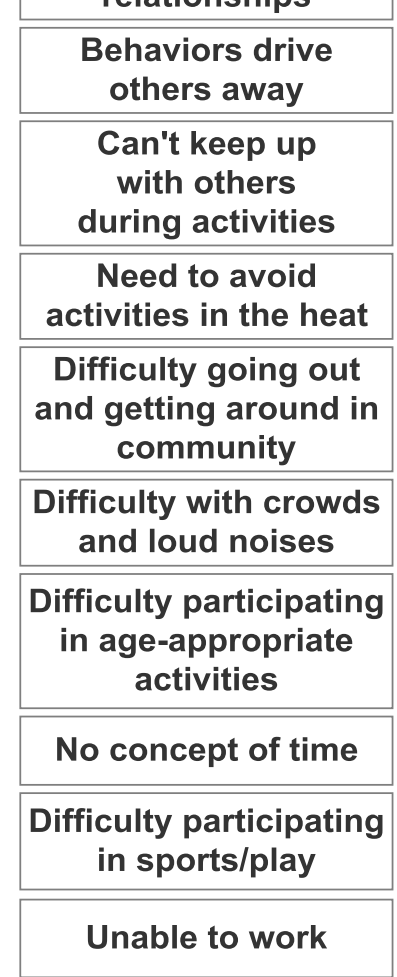

Key: *Specifically noted in both literature and interviews

reported that sleep problems improved with increasing age. Nine $(75 \%)$ caregivers of adults reported sleep problems versus 10 caregivers of adolescents (91\%) and eight caregivers of children $(73 \%)$.

\subsubsection{Patient Impacts}

Individuals with AS experience multiple impacts on activities of daily living, school, and social and community-related interactions. In general, individuals with AS lack independence and must rely on their caregivers for assistance to complete all of the basic activities of daily living. This need for total assistance continues across the lifespan.
Individuals with AS also experience challenges in school, due to absenteeism for health and sometimes behaviorrelated issues, and general challenges in learning and focusing, due to a short attention span and having cognitive deficits. They also can experience difficulties in participating in school functions, such as field trips or other group activities.

Patients are very impacted socially, despite their desire to interact with others, as their behaviors, such as the hair-pulling and hitting, can drive others away, impacting relationships inside and outside the home. Drooling, for example, can also create a social barrier. Physical challenges associated with walking or heat sensitivity can make it difficult to keep up with others, participate in play, or get around in the community. 


\section{Caregiver Impacts}

\begin{tabular}{|c|c|c|c|c|}
\hline Mental Health & Physical Health & Work & Home & Social \\
\hline $\begin{array}{c}\text { Need for constant } \\
\text { vigilance }^{*}\end{array}$ & Back problems* & $\begin{array}{l}\text { Quit work to care } \\
\text { for child* }\end{array}$ & \multirow{2}{*}{\begin{tabular}{|c|} 
Difficulty getting \\
things done at home \\
(chores, etc)*
\end{tabular}} & Isolation* \\
\hline & \multirow{3}{*}{$\begin{array}{l}\text { Injuries from } \\
\text { aggressive } \\
\text { behaviors }\end{array}$} & Ahconteoism* & & \multirow{2}{*}{$\begin{array}{l}\text { Impact on intimate } \\
\text { relationship* }\end{array}$} \\
\hline Worry/Anxiety* & & Adsenteeism & \multirow{2}{*}{\begin{tabular}{|c|}
$\begin{array}{c}\text { Difficulty caring for } \\
\text { other children* }\end{array}$ \\
\end{tabular}} & \\
\hline & & \multirow{3}{*}{$\begin{array}{c}\text { Decreased } \\
\text { productivity }\end{array}$} & & \multirow{2}{*}{$\begin{array}{c}\text { Impact on social } \\
\text { activities* }\end{array}$} \\
\hline Depression* & Poor sleep & & \multirow{2}{*}{\begin{tabular}{|c|} 
Managing complete \\
care of all of \\
the child's needs \\
\end{tabular}} & \\
\hline Guilt* & Fatigue & & & Difficult to plan* \\
\hline & \multirow{2}{*}{$\begin{array}{c}\text { Physical demands } \\
\text { of caring } \\
\text { for child }\end{array}$} & Works from home & \multirow{3}{*}{$\begin{array}{l}\text { Difficulty running } \\
\text { errands and } \\
\text { completing tasks } \\
\text { outside the home }\end{array}$} & Vacations* \\
\hline Sadness & & Changed job/career & & Relationships \\
\hline Worry & & & & \\
\hline Fear & & & \multirow{2}{*}{$\begin{array}{l}\text { Child destroys or } \\
\text { damages things } \\
\text { around the house }\end{array}$} & Need to plan ahead \\
\hline real & & & & Lack of support \\
\hline Frustration & & & \multirow{2}{*}{$\begin{array}{l}\text { Need to plan } \\
\text { family activities } \\
\text { around child }\end{array}$} & \\
\hline Stress & & & & \\
\hline
\end{tabular}

Key: *Specifically noted in both literature and interviews

Fig. 3 Caregiver impacts

\subsubsection{Caregiver Impacts}

The mental and physical health, work, home and social lives of caregivers are also impacted. The need to constantly be on alert causes stress, worry and anxiety, frustration, and fear. Caregivers also experience physical health issues, such as back pain from lifting or assisting their child and bruising, scratching and other injuries from aggressive behaviors. Sleep deprivation and exhaustion were frequently noted due to their child's sleep problems.

Caregivers are also impacted at work, with some changing jobs or careers, working from home, decreasing hours, or leaving the workforce entirely. Those who continue to work face issues with absenteeism and productivity.

Caregivers have difficulty completing tasks around the home, such as chores and errands. Life often revolves around the individual with AS, impacting decisions on family activities and causing challenges in caring for other children. It can also be a challenge ensuring the child doesn't destroy or damage the home due to their behaviors.

Caregivers also report difficulty with friendships, intimate relationships, and family relationships. They feel isolated and at times unsupported by others and have difficulty participating in social activities and planning and taking vacations.

\subsection{Cognitive Interviews}

\subsubsection{MPOMA-G}

In general, all three clinicians who participated in CI correctly interpreted the items and response options of the MPOMA-G, but there were a few issues noted with regard to item interpretation. Specifically, issues related to the items on step symmetry, step continuity, and trunk sway and their associated response options. Further clarification as to what should be considered when answering these questions was needed. Some of the clinicians felt that the MPOMA-G might be difficult to answer based on the age of the patient and their ability and/or motivation to walk. For instance, it may be difficult to use if a child or adult could only take a few steps. One clinician noted it may be easier if the scoring was done using a video recording of the patient walking instead of in person.

Overall, most items of the MPOMA-G were rated as highly relevant for use in AS by at least two out of three 
Table 5 Signs, symptoms and characteristics of Angelman syndrome (AS)—sample caregiver quotes

Cognitive and executive function

Seizures

Hyperactivity/restlessness

Social-emotional

Excitability

Anxiety

Emotional-expressive behavior

Behavior as communication

Effect on relationships

Sensory-compulsive behavior Water fascination

Food obsession

Physical

Sleep problems $\ldots$ they seem to $[\ldots]$ as he is getting older that they are changing; they're not the same type of seizures. (Caregiver of 9 year old)

... he's not very restless now. Um, I've really seen a big difference each year as he gets older. Very rest-like I would say he was always in cons-he was in constant motion before, not now, yeah. (Caregiver of 15 year old)

It's actually gotten better now that he's older, I think. Um, because he'll sit and watch, um, movies on Netflix or videos on YouTube, and he may change from one episode to the other or just that movie or video, but he's able to sit for long periods of time and just be content to sit there. (Caregiver of 12 year old)

I think he gets excited, but being more mature you know like because he's matured, but you know slowly. Being more mature, I think he almost like conscientious of if I' $m$ too outwardly like laughing and hugging and whatever that's not really appropriate. That's when he's - sort of the anxiety comes out. (Caregiver of 19 year old)

So, she gets anxious about wanting to go into a new place, um, and seeing somebody, you know, dealing with new people and that sort of thing. So, she just doesn't, you know, really want to go do new things very often. (Caregiver of 14 year old)

... I think a lot of times, again it goes back to that communication piece that it was probably her way of saying she was done or did not want to do it and her para or her helper did not get the-get the idea from her and so she kind of lashes out then. (Caregiver of 15 year old)

I think she's trying maybe to communicate something and she's not able to. That must be, uh, a frustrating, scary, uh, overwhelming feeling of not knowing what to-what's going on in your body and how to express what's going on or even - and then how do I tell the person that I need some help. (Caregiver of 17 year old)

It affects, like, his relationship with his sisters, because if they see him coming, you know, they're like oh, crap, I don't want my hair pulled today... (Caregiver of 5 year old)

Yeah, she has no, um, social relationships; her sisters don't want to spend any time with her at all. Um, so she really only has, you know, my husband and I, um, PCAs are her only real social, um, interaction. So it's really sad because she is so sociable, like she wants to be around other people, but we just can not. (Caregiver of 9 year old)

Sometimes on Saturdays we would take four or five baths because he likes to play in it. (Caregiver of 15 year old)

Um it definitely was more when he was younger um he-he's still loves water. He will try to fill the kitchen sink. Um he prefers baths over showers for that reason, because he can be in the tub and he can splash and he can move it and he can um be immersed in it. One time when he was little uh we had just gotten uh blow-up pool um for the yard, a small one. He was probably about 7 . And uh middle of the night I hear him crying. So I get up. Now wait a minute that doesn't sound right. And it - of course it came from outside. He had gotten himself up and out of the house, because he remembered it was there and he was sitting in the pool. And I have no idea how long he had been in there. (Caregiver of 21 year old)

Um, it really hasn't, you know, yeah, I mentioned, she was like that from the moment she was born, just always overeating. (Caregiver of 14 year old)

Way better, way better. When she was younger, she did not sleep. For the first 5 years of her life, she slept tops $4 \mathrm{~h}$ out of every 24 . You actually had to lay beside her and almost lay on top of her to get her to go to sleep. Her body was in constant motion, like hands flapping and smacking me around. (Caregiver of 28 year old) clinicians. As noted previously, one clinician, while an expert on AS, was not an expert on gait. This particular clinician rated some items as only moderately relevant for children with AS and suggested consideration be given to whether or not an individual is just learning to walk. Specifically, this included the right and left swing foot and the right and left foot clearance items.
Two of the three clinicians provided lower relevancy ratings for the step symmetry item for children with AS, and one also provided a lower rating for the adults. One clinician had a concern for consistency in his/her measurements, both with regard to adults and children with AS.

One clinician rated step continuity less relevant for both children and adults with AS, as he/she felt it was less studied 
Table 6 Patient and caregiver impacts—sample caregiver quotes

Patient impacts

Activities of daily living Well, [she] doesn't toilet herself at all. So-you know I do that. I bathe her, I dress her. I do everything. So-I brush her teeth, her hair. [...] Yeah. I mean, I have to cook her dinners, I have to make sure her wash, everything's done, everything's picked up clean, just all of it. I mean, it's day-to-day living. (Caregiver of 25 year old)

School No, he's-like if they're going on a class trip outside and it's too hot he can't do that. We can't go on family vacations in the summer to Florida like his other cousins and his grandmother and everybody just went as a family to Disney. We couldn't do that because it was just too hot for him to do so it has impacted his social life as well. (Caregiver of 16 year old)

Social/community Yeah, socially [drooling is] just a huge barrier. We've tried so hard to maintain his dignity with bandanas around his neck; he wears like a cowboy bandana. Uh, we send several with him everywhere he goes and it's just a constant fountain coming out of him. Uh, so adults and children alike tend to have quite a recoil response from physical contact with him, so that's really sad, because he likes to interact with people and they're like eeew, drool. (Caregiver of 8 year old)

Caregiver impacts

Mental health

Uh, well, we're completely depressed, I'm miserable... (Caregiver of 9 year old)

...the social isolation you feel...you know, you have friends but you feel very isolated from them. Because their life is nowhere near yours... you feel an isolation. You-it's a very lonely feeling to be a caregiver. It's a very scary feeling when you think about the future... But, um, I remain positive. I love my child, and, um, um, I wouldn't trade him for the world....and I'm blessed with him. But sometimes like it almost feels like you're a prisoner toto the syndrome. (Caregiver of 14 year old)

Physical health

Um, I think, other than just it wears you down, it makes you tired. Um, I know that there are a lot of Angel parents who have been doing this longer than me that their bodies are giving out. Um, and that's something that they've talked with me about. [laughter] You know, because it's like I can feel myself wearing down. But-and they said you don't know what's coming, you know. A lot, for some reason, a lot of Angel parents are being diagnosed with MS, and I don't know why. You know, I don't know what the deal with that is. So, um, we don't know what the long-term stress of this life is going to have on our health and how it's going to affect us, and that's something that is worrisome... (Caregiver of 8 year old)

Work [Laughs] Being very, very tired and trying to get lots of caffeine and not be cranky at everyone. [laughs] A lot of times, particularly, I mean my husband actually quit his job to stay at home with her. Um, he tries to buffer a lot of it, um, but it still wakes up, you know, the whole household, so when you go to work with only $4 \mathrm{~h}$ of sleep it's-I don't feel like I'm giving it my all at my work. I feel very, um, out of it, not thinking correctly. I'll come home and I'll be very tired, and sometimes very cranky, and I don't feel like I'm the mom I should be at home, especially for her and the other kids, because I'm just like I just want to go to bed. (Caregiver of 14 year old)

Home On a bad day he would — there's a few hours screaming and destroying property and, uh, making the house generally unlivable. (Caregiver of 8 year old)

Social Um, it - well, in terms of relationships, we are divorced or finishing up our divorce, so there are impacts in that area. Um, my spouse and the father of my children was not able to handle the situation. Um, he's not able to handle being woken up in the night and the extra challenges associated with the - a child with Angelman syndrome, as you know. So that's something that he cannot handle, so we had-um, he's no longer involved in any way, shape or form and he choose- he chooses not to be... (Caregiver of 8 year old)

...There have been times when she's in a seizure cycle where we've been like okay, we're not, you know, vacation cancelled, we'll just stay at home and just like hang out, stay in town, just stay near a hospital... (Caregiver of 7 year old)

and a more difficult concept to understand. All clinicians rated the trunk sway item as highly relevant for both children and adults with AS. One clinician rated walk stance as moderately relevant for both children and adults with AS. See Table 7 for sample quotes.

\subsubsection{Zeno Walkway ${ }^{\mathrm{Tm}}$}

One clinician reported that the Zeno Walkway ${ }^{\mathrm{TM}}$ was very relevant for individuals with $\mathrm{AS}$ and was a tool that could provide measurement in several key areas, such as gait speed, base of support, and angle of toe out. Another clinician noted that one benefit of the Zeno Walkway ${ }^{\mathrm{TM}}$ was that it was more objective than the MPOMA-G, but that it did not capture everything that might be important to measure, such as step symmetry and step continuity. See Table 7 for sample quotes.

\subsubsection{PEDI-CAT}

Most participants found the PEDI-CAT to be easy to understand and answer and relevant to AS. Some items required further clarification. For example, a few caregivers noted difficulty answering DA083 (using a TV remote) and DA098 (using a keypad) because they were not sure if they should 
Table 7 Cognitive interviews-sample clinician quotes

\begin{tabular}{|c|c|}
\hline \multicolumn{2}{|l|}{ MPOMA-G } \\
\hline $\begin{array}{l}\text { Right/left swing foot } \\
\text { and right/left clear } \\
\text { foot }\end{array}$ & $\begin{array}{l}\text { Again, I'm just thinking about children learning to walk where things are more difficult for them. The impact it has on } \\
\text { their life at an early stage might not be as great as it does when they're adults when they may be expected to move } \\
\text { around more or walk more, as opposed to kids just learning. People do provide a lot of support, and the expectations } \\
\text { are different for a child just learning to walk versus an adult who's maybe in the position of having to walk longer } \\
\text { distances or do more things independently }\end{array}$ \\
\hline Step symmetry & $\begin{array}{l}\text { I think given the difficulty that it was to administer, I would probably score it—gosh, I'd probably say a } 3 \ldots . . \text { I think } \\
\text { because I'm not sure I was consistent when I was observing the gait, I was scoring this in a reliable way, so this was } \\
\text { one of those test items that as I'm scoring it, I'm always thinking-you know, I'm trying to relate it to the other tests } \\
\text { that I had administered for other patients to think am I being consistent here? }\end{array}$ \\
\hline \multicolumn{2}{|l|}{ Zeno Walkway ${ }^{\mathrm{TM}}$} \\
\hline Relevancy & $\begin{array}{l}\text { I actually think it does a couple of things. It actually gives us some of the measures that we're looking for, that you're } \\
\text { looking at in the MPOMA-G and for the modified POMA-g, and I think it is a way of quantifying in the clinic that } \\
\text { doesn't require gait laps and the gait characteristics of patients with Angelmans, including gait speed, including base } \\
\text { of support, including angle of toe out, which isn't really captured in other areas, so I think those types of measures } \\
\text { are helpful to kind of determine progress or regression with gait } \\
\text { Gosh, you know, I have no idea if it's better or worse than an observer scoring the MPOMA. I would think you're } \\
\text { going to get much more-oh, shall we say objective data from the Walkway than you would from the MPOMA, just } \\
\text { because there are human beings involved in the MPOMA and the Walkway sort of takes that out of the mix, but it } \\
\text { certainly is going to be able to allow you to assess stride length and wide base of gait. I don't know that it can help } \\
\text { you with symmetry and step continuity, so I think it's got some relevance, but I'm not sure it fits the entire bill of } \\
\text { what's needed, ....We just don't know. Well, maybe I should say 3, because I don't think it can capture everything, } \\
\text { but what it does capture, it captures much more objectively }\end{array}$ \\
\hline
\end{tabular}

MPOMA-G Modified Performance-Oriented Mobility Assessment

be thinking about intention or just physical ability. See Table 8 for sample quotes.

Participants interpreted relevancy differently. Items received lower ratings if the patient had already mastered the skill, was unable to perform the activity, was not allowed to perform the task for safety concerns, and/or if the skill was viewed as less important. The majority of participants found the items highly relevant, as they relate to activities necessary for independence.

\subsubsection{ABC-C}

The ABC-C was generally found to be easy to understand and complete. Item relevancy varied, but the majority of items (33 out of 58 items) were rated as highly relevant by at least $42 \%$ of caregivers. All items were rated as highly relevant by at least two caregivers $(2,6 \%)$. Some items (e.g., Item 9. 'Talks excessively') were considered less relevant due to the mostly non-verbal nature of this population. These items need further clarification to note whether body gestures or vocalizations should be considered when responding. See Table 8 for sample quotes.

Items related to activity levels were also problematic for some. Questions on underactivity were less relevant for children with AS, who tend to be more hyperactive, while the hyperactivity items were less relevant for some teens and adults, who had outgrown hyperactivity. Items on isolation or lack of interest in social interactions were also reported to be less relevant.

\subsubsection{ADAMS}

Overall, caregivers found the ADAMS instructions and response scale to be clear and easy to understand and complete. However, some items were interpreted inconsistently, such as Item 1. 'Nervous,' Item 7. 'Tense,' Item 10. 'Sad,' and Item 23. 'Listless.'

Relevancy ratings varied considerably, with more caregivers giving ratings of 'not at all relevant' than 'extremely relevant.' For instance, Item 5. 'Sleeps more than normal' was problematic. While sleep was considered important, oversleeping was not a concern. Items relating to communication were also problematic. See Table 8 for sample quotes.

\subsubsection{Morning Diary}

The Morning Diary was found to be highly relevant for use with children and adults with AS. A majority of caregivers found that the questions in the four primary groups of items-night waking, disruptive behavior, subject coming out of the bedroom, and caregiver sleeping with subjectto be highly relevant. However, the instrument's wording and dual diary structure, with some questions designed to capture the caregiver's experience and some to capture the patient's experience, caused confusion, demonstrating a need for the instrument to be further refined. For example, on the question in the caregiver diary on night waking, some caregivers were unsure as to what should be considered. See Table 8 for sample quotes. Some caregivers also expressed 
Table 8 Cognitive interviews-sample caregiver quotes

\begin{tabular}{|c|c|}
\hline \multicolumn{2}{|l|}{ PEDI-CAT } \\
\hline DA083 Using a TV remote control & $\begin{array}{l}\text { Yeah, and that's just because it's, you know, appropriately, is a word that I would definitely add to that. } \\
\text { [...] I mean, he goes for the remotes all the time, but it's more so just attention seeking, he's not, you } \\
\text { know, purposefully looking or changing the channel. (Caregiver of } 16 \text { year old) }\end{array}$ \\
\hline $\begin{array}{l}\text { DA098 Presses buttons to operate } \\
\text { a key-pad such as a phone or } \\
\text { ATM }\end{array}$ & $\begin{array}{l}\text { Okay, so, again, this one I linked it—she presses it and she presses it easily but she doesn't press it like } \\
\text { well, you know, like, you know what I mean, like she knows that she's like, oh a phone and I want to } \\
\text { play with it or I want to do this... (Caregiver of } 7 \text { year old) }\end{array}$ \\
\hline \multicolumn{2}{|l|}{$\mathrm{ABC}-\mathrm{C}$} \\
\hline Item 9. Talks excessively & $\begin{array}{l}\text { Just because she does, you know, she doesn't talk, but she says, you know "mama, baba," things like that } \\
\text { a lot. [laughs] (Caregiver of } 15 \text { year old) } \\
\text { Zero... Because he doesn't talk (Caregiver of } 15 \text { year old) }\end{array}$ \\
\hline \multicolumn{2}{|l|}{ ADAMS } \\
\hline Item 1. Nervous & ...I'm not sure what the difference is between nervous and anxiety.... (Caregiver of 28 year old) \\
\hline Item 7. Tense & $\begin{array}{l}\text { I did not really know that one, so I gave it a zero... Because I did not know if it was like, your muscles } \\
\text { "tense," because he is tight but all the rest of these are like brain things.....So I did not know if that was } \\
\text { right or not. (Caregiver of } 15 \text { year old) }\end{array}$ \\
\hline Item 10. Sad & $\begin{array}{l}\text { Both \#10 [sad] and \#11 [worried] are like \#1 [nervous]; it's me projecting onto him all of that. So I think } \\
\text { he's not acting sad, but that's not really-I mean, they're asking me if it's a behavior. So he doesn't look } \\
\text { like he's behaving sad to me. So it's kind of complicated. (Caregiver of } 18 \text { year old) }\end{array}$ \\
\hline Item 23. Listless & “Listless,” I don't know what that means. (Caregiver of 11 year old) \\
\hline Item 5. Sleeps more than normal & $\begin{array}{l}\text { Um, okay, that's an interesting question because I will say a } 5 \text { because the issue of sleep is very impor- } \\
\text { tant for Angelman syndrome families and their-their kids, uh, because they lack the sleep, so it is a } \\
\text { big issue, it's a 5, but, uh, she doesn't have a problem over-sleeping. We wish that she will sleep more. } \\
\text { [laughter] (Caregiver of } 17 \text { year old) } \\
\text { Sleeps more than normal, uhh, that would be a godsend. Is it relevant in Angelman syndrome? I mean, if } \\
\text { they started sleeping more than normal that could be like the best outcome that any medication could } \\
\text { ever have. (Caregiver of } 18 \text { year old) }\end{array}$ \\
\hline \multicolumn{2}{|l|}{ Morning Diary } \\
\hline Night waking & $\begin{array}{l}\text { Yes, because I was trying to think about, am I only supposed to be thinking about my night waking based } \\
\text { on her night waking, or, am I thinking about my life, too? (Caregiver of } 19 \text { year old) } \\
\text { Yes, because I wasn't certain if it was asking about the subject or myself. (Caregiver of } 14 \text { year old) }\end{array}$ \\
\hline
\end{tabular}

$A B C-C$ Aberrant Behavior Checklist-Community, ADAMS Anxiety, Depression and Mood Scale, PEDI-CAT Pediatric Evaluation of Disability Inventory Computer Adaptive Test

concern about their ability to answer some of the questions, particularly if they were not awake or physically present to observe their child.

\section{Discussion}

This is the first study to conduct in-depth, qualitative interviews with caregivers of children, adolescents, and adults with AS. Patient, caregiver, and clinician insights play an important role in the drug development process and can inform the appropriate and relevant selection of endpoints in clinical trials [5, 6]. This insight provides a deep understanding of the impacts of AS on patients and their caregivers. As such, the findings of this study are instrumental in providing guidance in identifying the concepts that are most important to patients and caregivers. Researchers can then be sure these important concepts are being captured and appropriately measured in the context of a clinical trial. The insight provided in this study informed the development of the first conceptual model of AS.

This study also highlights patient-relevant and potentially appropriate measures that could be used in AS clinical trials. The identified measures meet some, if not all, of FDA guidance for COA assessments in related diseases, but have not been previously evaluated for content validity specifically for use in children and adults with AS.

While the instruments each covered relevant concepts for AS, particularly those related to mobility, fine and gross motor skills, sleep, and behavior-related issues, not one instrument covered all domains or was completely ready for use without adaptation in order to be fully applicable to an adult or child with AS, particularly to account for the mostly non-verbal population, as items related to speech and verbal communication are not relevant, and non-observable symptoms are difficult for a caregiver to assess. Furthermore, as individuals with AS age, the characteristics and impacts of AS also may change; therefore, developing separate instruments for children and adults 
is important. Additionally, areas that are not well covered by any of the measures are the more distal impacts of AS, such as school, relationships, and social interactions. Those with AS seek out social interaction, but their difficulty communicating and aggressive behaviors hinder their ability to socialize with their peers and others in the community. Similarly, the measures do not address the substantial impact that caring for a child with AS has on the caregiver and family overall. Caregivers experience fatigue and other physical impairments related to the demands of providing full-time care for their children through adulthood. Caregiving also can affect spousal and family relationships and make engaging in social activities and maintaining friendships more challenging. The need to provide constant care takes an emotional toll on caregivers, causing stress, worry, frustration, and fear [28].

It is important to note a few study limitations. Caregiver selection was limited to those who responded to study advertisements via two patient advocacy groups and may not be representative of all caregivers of an individual with AS. Additionally, for the clinician CI, due to the rare nature of AS, it was difficult to identify and enroll clinicians who had expertise in AS and gait. Therefore, participants with expertise in AS were enrolled, even if they were not gait experts. Also, this study focused on ambulatory patients with AS, so results may not apply to those who are non-ambulatory.

\section{Conclusion}

AS is a condition that affects individuals in a number of domains (e.g., behavior, motor and communication ability, and sleep) and their overall ability to be independent. All six instruments demonstrated that each could provide important and useful information relevant to the AS population; however, each instrument is problematic in that it either contains items found not to be relevant to individuals with AS or is missing concepts found to be important based on the interviews. Moreover, no single instrument covers all relevant domains specific to AS. Therefore, there is supportive evidence that future work should consider the adaptation of existing COAs and the development of a novel Angelman-specific instrument that could be implemented in clinical research to ensure that outcomes important to patients and caregivers are considered as part of the benefit and risk assessment of new treatments.

Data Availability The qualitative interview data generated during and/or analyzed during the current study are proprietary and not publicly available but may be available from the corresponding author on reasonable request.
Acknowledgements The authors would like to acknowledge Kelly Lipman, Marie de la Cruz, and Christopher Davey for their assistance with the qualitative interviews and Linda Abetz-Webb for her contribution to the literature review.

Author Contributions JG and JV participated in study design, development of the conceptual model, and writing of the manuscript. BR and EF participated in developing the study design, conducting interviews, analyzing the data, developing the conceptual model, and writing the manuscript.

\section{Compliance with Ethical Standards}

Funding statement This study was funded by Ovid Therapeutics.

Conflict of Interest J.C. Grieco, R. Cabo, and J. Visootsak are employees of Ovid Therapeutics and own stock in Ovid Therapeutics. B. Romero and E. Flood are employees of ICON, which was hired by Ovid to conduct this study.

Ethics/Consent This study received approval from Salus IRB (Austin, TX, USA), a central institutional review board. All study participants provided written informed consent.

Ethical Approval All procedures performed in studies involving human participants were in accordance with the ethical standards of the institutional and/or national research committee and with the 1964 Helsinki declaration and its later amendments or comparable ethical standards.

Open Access This article is distributed under the terms of the Creative Commons Attribution-NonCommercial 4.0 International License (http://creativecommons.org/licenses/by-nc/4.0/), which permits any noncommercial use, distribution, and reproduction in any medium, provided you give appropriate credit to the original author(s) and the source, provide a link to the Creative Commons license, and indicate if changes were made.

\section{References}

1. Williams CA, Beaudet AL, Clayton-Smith J, Knoll JH, Kyllerman M, Laan LA, Magenis RE, Moncla A, Schinzel AA, Summers JA, Wagstaff J. Angelman syndrome 2005: updated consensus for diagnostic criteria. Am J Med Genet. 2006;140A:413-8. https:// doi.org/10.1002/ajmg.a.31074.

2. Dagli A, Buiting K, Williams CA. Molecular and Clinical Aspects of Angelman Syndrome. Mol Syndromol. 2012;2(3-5):100-12.

3. Clayton-Smith J, Laan LA. Angelman syndrome: a review of the clinical and genetic aspects. J Med Genet. 2003;40(2):87-95.

4. Food and Drug Administration (FDA); US Department of Health and Human Services; Center for Drug Evaluation and Research (CDER); Center for Biologics Evaluation and Research (CBER); Center for Devices and Radiological Health (CDRH). Guidance for Industry Patient-Reported Outcome Measures: Use in Medical Product Development to Support Labeling Claims. 2009. https ://www.fda.gov/downloads/Drugs/GuidanceComplianceRegulat oryInformation/Guidances/UCM193282.pdf 21-01-18. Accessed 21 Jan 2018

5. Lowe MM, Blaser DA, Cone L, Arcona S, Ko J, Sasane R, Wicks P. Increasing patient involvement in drug development. Value in Health. 2016;19(6):869-78. 
6. Perfetto EM, Burke L, Oehrlein EM, Epstein RS. Patient-focused drug development: a new direction for collaboration. Med Care. 2015;53(1):9-17.

7. Peters SU, Bird LM, Kimonis V, Glaze DG, Shinawi LM, Bichell TJ, Barbieri-Welge R, Nespeca M, Anselm I, Waisbren S, Sanborn E. Double-blind therapeutic trial in Angelman syndrome using betaine and folic acid. Am J Med Genet Part A. 2010;152(8):1994-2001.

8. Bird LM, Tan WH, Bacino CA, Peters SU, Skinner SA, Anselm I, Barbieri-Welge R, Bauer-Carlin A, Gentile JK, Glaze DG, Horowitz LT. A therapeutic trial of pro-methylation dietary supplements in Angelman syndrome. Am J Med Genet Part A. 2011;155(12):2956-63.

9. Huang HS, Burns AJ, Nonneman RJ, Baker LK, Riddick NV, Nikolova VD, Riday TT, Yashiro K, Philpot BD, Moy SS. Behavioral deficits in an Angelman syndrome model: effects of genetic background and age. Behav Brain Res. 2013;243:79-90.

10. Mabb AM, Simon JM, King IF, Lee HM, An LK, Philpot BD, Zylka MJ. Topoisomerase 1 regulates gene expression in neurons through cleavage complex-dependent and-independent mechanisms. PLoS One. 2016. https://doi.org/10.1371/journ al.pone.0156439.

11. Plasschaert RN, Bartolomei MS. Autism: a long genetic explanation. Nature. 2013;501(7465):36.

12. Meng L, Ward AJ, Chun S, Bennett CF, Beaudet AL, Rigo F. Towards a therapy for Angelman syndrome by targeting a long non-coding RNA. Nature. 2015;518(7539):409.

13. Bailus BJ, Pyles B, McAlister MM, O'geen H, Lockwood SH, Adams AN, Nguyen JT, Yu A, Berman RF, Segal DJ. Protein delivery of an artificial transcription factor restores widespread Ube3a expression in an Angelman syndrome mouse brain. Mol Ther. 2016;3:548-55.

14. Grieco JC, Ciarlone SL, Gieron-Korthals M, Schoenberg MR, Smith AG, Philpot RM, Heussler HS, Banko JL, Weeber EJ. An open-label pilot trial of minocycline in children as a treatment for Angelman syndrome. BMC Neurol. 2014;1:232.

15. Frater A. Health outcomes: a challenge to the status quo. Qual Health Care. 1992;1(2):87-8.

16. Ferrans CE, Zerwic JJ, Wilbur JE, Larson JL. Conceptual model of health-related quality of life. J Nurs Scholarsh. 2005;37(4):336-42.

17. Wheeler AC, Sacco P, Cabo R. Unmet clinical needs and burden in Angelman syndrome: a review of the literature. Orphanet J Rare Dis. 2017;12:164-81.
18. Abetz-Webb L, Cabo R, Grieco J, Rakhit A, During M. Conceptual model and clinical outcomes assessments for Angelman's syndrome: utilizing pragmatic methods in rare diseases. Value Health. 2016;19(7):A386.

19. Allen KD, Kuhn BR, DeHaai KA, Wallace DP. Evaluation of a behavioral treatment package to reduce sleep problems in children with Angelman syndrome. Res Dev Disabil. 2013;34:676-86.

20. Phillips D, Griffin D, Przybylski T, Morrison E, Reeves A, Vallee M, Fujita K, Madson K, Whyte M. A modified performanceoriented mobility assessment tool for assessing clinically relevant gait impairments and change in children with hypophosphatasia: development and validation. Bone Abstract. 2015;4:136.

21. Gouelle A, Leroux J, Bredin J, Megrot F. Changes in gait variability from first steps to adulthood: nromative data for the gait variability Index. J Motor Behavior. 2015;48(3):249-55.

22. Haley SM, Coster WJ, Dumas HM, Fragala-Pinkham MA, Moed R. PEDI-CAT: development, standardization and administration manual. Boston: Boston University; 2012.

23. Esbensen AJ, Rojahn J, Aman MG, Ruedrich S. Reliability and validity of an assessment instrument for anxiety, depression, and mood among individuals with mental retardation. J Autism Dev Disord. 2003;33(6):617-29.

24. Aman MG, Singh NN, Stewart AW, Field CJ. The aberrant behavior checklist: a behavior rating scale for the assessment of treatment effects. Am J Ment Defic. 1985;89(5):485-91.

25. Joffe H, Yardley L. Content and thematic analysis. In: Marks D, Yardley L, editors. Research methods for clinical and health psychology. London: Sage; 2004. p. 56-68.

26. MaxQDA, software for qualitative data analysis, 1989-2018, VEBI Software-Consult-Sozialforschung GmbH, Berlin, Germany.

27. Kerr C, Nixon A, Wild D. Assessing and demonstrating data saturation in qualitative inquiry supporting patient-reported outcomes research. Expert Rev Pharmacoecon Outcomes Res. 2010;10(3):269-81.

28. Griffith GM, Hastings RP, Oliver C, Howlin P, Moss J, Petty J, Tunnicliffe P. Psychological well-being in parents of children with Angelman, Cornelia de Lange and Cri du Chat syndromes. J Intellect Disabil Res. 2011;55(4):397-410. 